Сущенко О.А., Безкоровайний Ю.М., Новицька Н.Д., Голіцин В.О.

\title{
СИНТЕЗ РОБАСТНОГО РЕГУЛЯТОРА БПЛА ДЛЯ ВИПАДКУ НЕОРТОГОНАЛЬНОЇ КОНФІГУРАЦІЇ ІНЕРЦІАЛЬНИХ ДАТЧИКІВ
}

Статтю зосереджено на проблемах синтезу робастних систем управління, призначених для експлуатації на безпілотних літальних апаратах. Головною метою дослідження $\epsilon$ розробка алгоритму синтезу робастного закону управління рухом безпілотного літального апарата за умови використання неортогонального вимірювача, щзо являе собою надмірну конфігурачію гіроскопічних датчиків, побудованих на технологіях мікроелектромеханічних систем. Розробку регулятора було виконано на основі робастного структурного синтезу. Для досягнення поставленої мети було розроблено модель поздовжнього руху безпілотного літального апарата. Матриці стану, управління та спостереження цієї моделі було визначено за допомогою технології Aerosim засобами системи MatLab.

Для розв'язання поставленої проблеми було використано методи теорії управління польотом у частині створення моделі поздовжнього руху безпілотного літального апарата; методи побудування надмірних неортогональних конфігурацій інерцальних датчиків рухомих об'єктів; методи сучасної теорії управління у частині створення алгоритмів робастного структурного синтезу та методи математичного моделювання.

У статті представлено результати моделювання синтезованої системи у вигляді перехідних прочесів для вхідних ступінчатих та імпульсних впливів. Наведені графічні залежності демонструють високу якість прочесів управління в умовах дї збурюючи впливів. Отримані результати можуть бути корисними для рухомих об'єктів широкого класу, на яких використовуються надмірні вимірювальні системи, але найбільш доцільно їх використання в проблематиці управління безпілотними літальними апаратами.

Ключові слова: система управління, неортогональний прилад, інерчіальний датчик, надмірність, робастний регулятор

Вступ. У наш час використання безпілотних літальних апаратів (БПЛА) є одним із сучасних напрямів розвитку авіації. Найбільш важливими застосуваннями БПЛА є повітряні зйомки, моніторинг параметрів оточуючого середовища у важкодоступних місцевостях та ін. Функціонування БПЛА здійснюється в складних умовах, що супроводжуються дією параметричних та координатних збурень. Забезпечення високої точності вищезгаданих процесів спостереження може бути здійснено за допомогою робастного управління рухом БПЛА. Зазвичай вимірювання навігаційної інформації на борту БПЛА здійснюється за допомогою таких інерціальних датчиків як акселерометри та гіроскопічні пристрої, побудовані на основі мікроелектромеханічних (MEMC) технологій. Такий підхід забезпечує низьку вартість, малі розміри та низьке енергоспоживання інерціальної вимірювальної системи. У той же час залишається актуальною проблема підвищення точності та надійності вимірювань з огляду на показники точності існуючих інерціальних МЕМС-вимірювачів. Для підвищення точності системи вимірювання навігаційної інформації на борту БПЛА можливе використання структурної надмірності первинних навігаційних вимірювачів на основі неортогональної орієнтації їх осей чутливості [1].

Існує декілька підходів до реалізації структурної надмірності інерціальних навігаційних датчиків. Перший підхід полягає у застосуванні власне надмірних вимірювачів. Але в цьому випадку зростають обчислювальні ресурси, необхідні для оброблення навігаційної інформації. Інакше кажучи, необхідно використовувати процесор високої потужності, що 
ускладнює архітектуру та підвищує вартість навігаційної системи у цілому. Другий підхід полягає у використанні надмірних окремих складових навігаційних вимірювачів. При цьому вимоги до обчислювальної потужності та пропускної спроможності інформаційних каналів значно зменшуються. Отже переваги другого підходу до реалізації структурної надмірності $\epsilon$ очевидними [2].

Постановка проблеми Узагальнену структуру навігаційної системи БПЛА із використанням надмірності представлено на рис. 1.

Використання неортогональних надмірних конфігурацій інерціальних вимірювачів навігаційної інформації, заснованих на МЕМС-датчиках, має деякі переваги. По-перше, такі конфігурації забезпечують зменшення зміщення нуля. Слід зазначити, що наявність зміщення нуля $\epsilon$ однією з важливих проблем експлуатації сучасних МЕМС-датчиків. Отже, використання неортогональних надмірних конфігурацій підвищує точність вимірювань навігаційної інформації. По-друге, значно підвищується надійність вимірювань завдяки надмірності. По-третє, у такий конфігурації забезпечується можливість розміщення більшої кількості датчиків у межах конструктивного блоку з тими самими розмірами. Ця перевага $\epsilon$ корисною навіть за умови мініатюризації сучасних інерціальних датчиків. Додатковою перевагою є можливість підвищення відмовостійкості навігаційних систем.

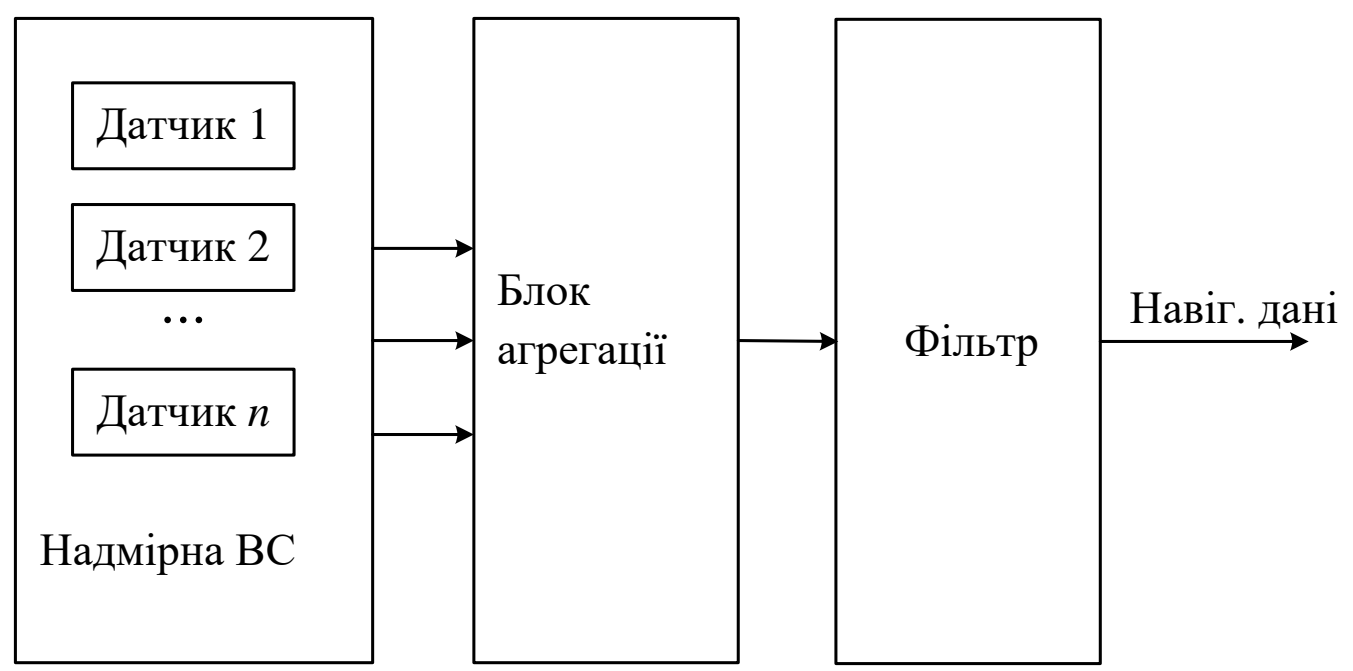

Рис. 1. Структурна схема надмірної навігаційної системи ВС - вимірювальна система.

Постановка проблеми потребує розв'язання декількох взаємопов'язаних задач. Перша задача полягає у виборі неортогональної надмірної конфігурації інерціальних вимірювачів та розробці алгоритму агрегації. Головною метою розробки алгоритму агрегації $є$ перетворення інформації, що надходить від надмірних MEMC-вимірювачів, у проекції кінематичних параметрів (прискорень, кутових швидкостей) на осі навігаційної системи координат. Друга задача полягає у проектуванні робастного регулятора. У цьому випадку може бути застосований $H_{\infty}$-синтез, який являє собою метод робастного структурного синтезу. Структурна схема управління рухом БПЛА показана на рис. 2.

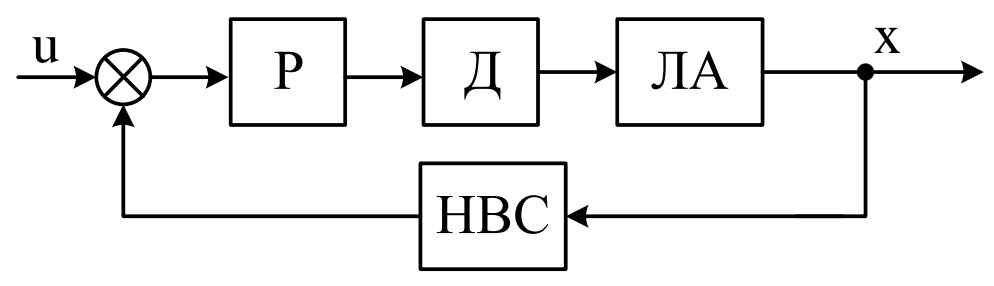

Рис. 2. Структурна схема управління рухом: Р - регулятор; Д - двигун; НВС - надмірна вимірювальна система. 
Вибір неортогональних конфігурацій інерціальних датчиків. Вибір конфігурації інерціальних датчиків зумовлено умовами роботи БПЛА.

Різні типи неортогональних конфігурацій на основі МЕМС-вимірювачів представлено у праці [3]. 3 метою спрощення процесу проектування робастної системи доцільно розглядати неортогональні конфігурації, засновані на одноосних датчиках. Відомо, що в основу неортогональної конфігурації може бути покладено таку геометричну фігуру як конус [4]. Осі чутливості поодиноких датчиків можуть бути розташовані уздовж утворюючих конуса та осі його симетрії.

Результати порівняльного аналізу точності різних неортогональних конфігурацій одноосних інерціальних датчиків представлено у табл. 1 [5]. Вона містить дані про значення сліду кореляційної матриці похибок для різних неортогональних конфігурацій та різних ситуацій відмов датчиків.

Результати порівняльного аналізу точності неортогональних конфігурацій Таблиця 1 інерціальних датчиків

\begin{tabular}{|r|c|l|c|c|}
\hline \multirow{2}{*}{ № } & \multicolumn{2}{|c|}{ Тип конфігурації } & \multicolumn{3}{|c|}{ Слід кореляційної матриці похибок } \\
\cline { 3 - 5 } & & $\begin{array}{l}\text { без } \\
\text { відмов }\end{array}$ & $\begin{array}{c}2 \\
\text { відмови }\end{array}$ & $\begin{array}{c}3 \\
\text { відмови }\end{array}$ \\
\hline 1 & 5 датчиків уздовж утворюючих конуса & 2,21 & 3,20 & 3,92 \\
\hline 2 & 6 датчиків уздовж утворюючих конуса & 1,79 & 2,13 & 4,50 \\
\hline 3 & $\begin{array}{c}4 \text { датчика уздовж утворюючих конуса та } \\
1 \text { уздовж осі симетрії }\end{array}$ & 1,93 & 3,15 & 5,00 \\
\hline 4 & $\begin{array}{c}5 \text { датчиків уздовж утворюючих конуса } \\
\text { та 1 уздовж осі симетрії }\end{array}$ & 1,70 & 2,18 & 3,35 \\
\hline
\end{tabular}

Відповідно до даних, наведених у табл. 1, найкращим варіантом є четвертий.

Математична модель БПЛА. Представлена проблема може бути розв'язана на прикладі БПЛА «Аерозонд», який являє собою малий БПЛА, призначений для спостереження погодних умов, включаючи температуру, атмосферний тиск, вологість та вплив вітру над океаном та віддаленими територіями [6]. Лінеаризована модель аерозонду як об'єкта управління може бути представлена у просторі станів

$$
\left\{\begin{array}{l}
\dot{\mathbf{x}}=\mathbf{A x}+\mathbf{B u} \\
\mathbf{y}=\mathbf{C} \mathbf{x}+\mathbf{D u}
\end{array}\right. \text {. }
$$

Динаміка поздовжнього руху аерозонду може бути описана вектором стану [6, 7]

$$
\mathbf{x}=[v, w, q, \theta, h, \Omega]^{\mathrm{T}},
$$

де $v, w$ - горизонтальна та вертикальна складові повітряної швидкості; $q$ - кутова швидкість тангажу; $\theta$ - кут тангажу; $h$ - висота польоту; $\Omega$ - швидкість двигуна. Управління поздовжнім рухом здійснюється за допомогою керма висоти та управління тягою двигунів.

Отже, вектор управління виглядає як

$$
u=\left[\delta_{e}, \delta_{t h}\right]^{\mathrm{T}},
$$

де $\delta_{e}, \delta_{t h}-$ відхилення керма висоти та керма управління тягою двигуна.

Вектор вихідних сигналів може бути представлений у вигляді

$$
\mathbf{y}=\left[V_{a}, \alpha, q, \theta, h\right],
$$

де $V_{a}$ - істинна повітряна швидкість, $\alpha-$ кут атаки.

Отже, лінеаризовані рівняння поздовжнього руху є такими 


$$
\left\{\begin{array}{l}
\dot{v}=Y_{v} v+Y_{w} w+Y_{q} q+Y_{\theta} \theta+Y_{h} h+Y_{\Omega} \Omega+Y_{\delta_{e}} \delta_{e}+Y_{\delta_{t h}} \delta_{t h} \\
\dot{w}=Z_{v} v+Z_{w} w+Z_{q} q+Z_{\theta} \theta+Z_{h} h+Z_{\Omega} \Omega+Z_{\delta_{e}} \delta_{e}+Z_{\delta_{t h}} \delta_{t h} ; \\
\dot{q}=M_{v}^{y} v+M_{w}^{y} w+M_{q}^{y} q+M_{\theta}^{y} \theta+M_{h}^{y} h+M_{\Omega}^{y} \Omega+M_{\delta_{e}}^{y} \delta_{e}+M_{\delta_{t h}}^{y} \delta_{t h} ; \\
\dot{\theta}=H_{\omega_{y}}^{-1} q ; \\
\dot{h}=\theta+H_{v} v+H_{w} w ; \\
\dot{\Omega}=h+T_{v} v+T_{w} w+T_{\delta_{t h}} \delta_{t h} .
\end{array}\right.
$$

Неортогональність інерціального вимірювача у рівняннях (6) враховується за допомогою матриці перетворень навігаційної інформації $H_{\omega_{y}}^{-1}$.

Беручи до уваги вираз (2), матриці А і В моделі у просторі станів (1) можуть бути представлені у такому вигляді

$$
\mathbf{A}=\left[\begin{array}{cccccc}
Y_{v} & Y_{w} & Y_{q} & Y_{\theta} & Y_{h} & Y_{\Omega} \\
Z_{v} & Z_{w} & Z_{q} & Z_{\theta} & Z_{h} & Z_{\Omega} \\
M_{v} & M_{w} & M_{q} & M_{\theta} & M_{h} & M_{\Omega} \\
0 & 0 & H_{\omega_{y}}^{-1} & 0 & 0 & 0 \\
H_{v} & H_{w} & 0 & 1 & 0 & 0 \\
T_{v} & T_{w} & 0 & 0 & 1 & 0
\end{array}\right], \quad \mathbf{B}=\left[\begin{array}{cc}
Y_{\delta_{e}} & Y_{\delta_{t h}} \\
Z_{\delta_{e}} & Z_{\delta_{t h}} \\
M_{y} & M_{y} \\
0 & 0 \\
0 & 0 \\
0 & T_{\delta_{t h}}
\end{array}\right] .
$$

Елементи матриці А (3) визначаються аеродинамікою БПЛА та конструкцією двигуна.У виразах (3) матрицю В представлено для загального випадку, коли існує два управління [7, 8].

Синтез робастного управління потребує використання моделей у просторі станів (1). Для вищезгаданого БПЛА матриці моделі у просторі станів можуть бути отримані за допомогою пакета AeroSim обчислювальної системи MatLab [9]. Отже. матриці стану, управління та спостереження у числовому вигляді набувають вигляду

$$
\begin{gathered}
\mathbf{A}=\left[\begin{array}{cccccc}
-0.1956 & 0.7253 & -1.9446 & -9.7757 & -0.0001 & 0.0099 \\
-0.6170 & -3.6757 & 19.4157 & -0.9719 & 0.001 & 0 \\
0.5233 & -3.7373 & -3.8346 & 0 & 0 & -0.0068 \\
0 & 0 & 1.000 & 0 & 0 & 0 \\
0.0989 & -0.9951 & 0 & 19.9998 & 0 & 0 \\
26.2099 & 2.6058 & 0 & 0 & -0.0118 & -2.0073
\end{array}\right] \\
\mathbf{B}=\left[\begin{array}{cc}
-0.9669 & 2.4680 \\
-77.6673 & 1.3287 \\
-3.0995 & -14.1149 \\
0 & 0 \\
0 & 0
\end{array}\right] ; \tilde{\mathbf{N}}=\left[\begin{array}{ccccc}
0.05 & 0 & 0 & 0 & 0 \\
0 & 1 & 0 & 0 & 0 \\
0 & 0 & 1 & 0 & 0 \\
0 & 0 & 0 & 1 & 0 \\
0 & 0 & 0 & 0 & 1
\end{array}\right]
\end{gathered}
$$

Рівняння бічного руху можуть бути отримані в аналогічний спосіб $[10,11]$.

Робастний структурний синтез. $H_{\infty}$-синтез $є$ потужний інструмент проектування систем управління із зворотним зв'язком на основі визначення частотних характеристик як функцій сингулярних чисел. Відомий підхід до проектування робастних систем, коли умова робастної стійкості формулюється у термінах норм, обмежених ваговими передатними функціями. Цей підхід реалізовано у таких автоматизованих засобах оптимального проектування як Robust Control Toolbox [12]. 
Результати моделювання синтезованої системи для каналу поздовжнього руху представлені на рис. 3, 4.
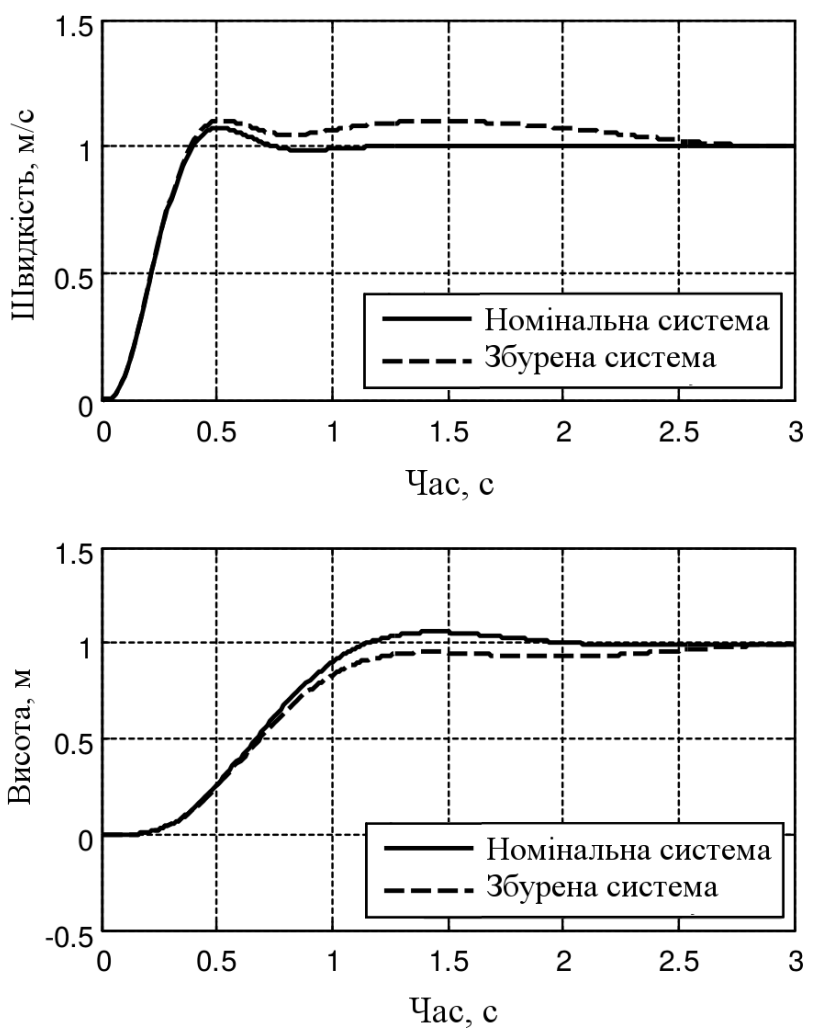

Рис. 3. Результати моделювання синтезованої системи для вхідного ступінчастого впливу.
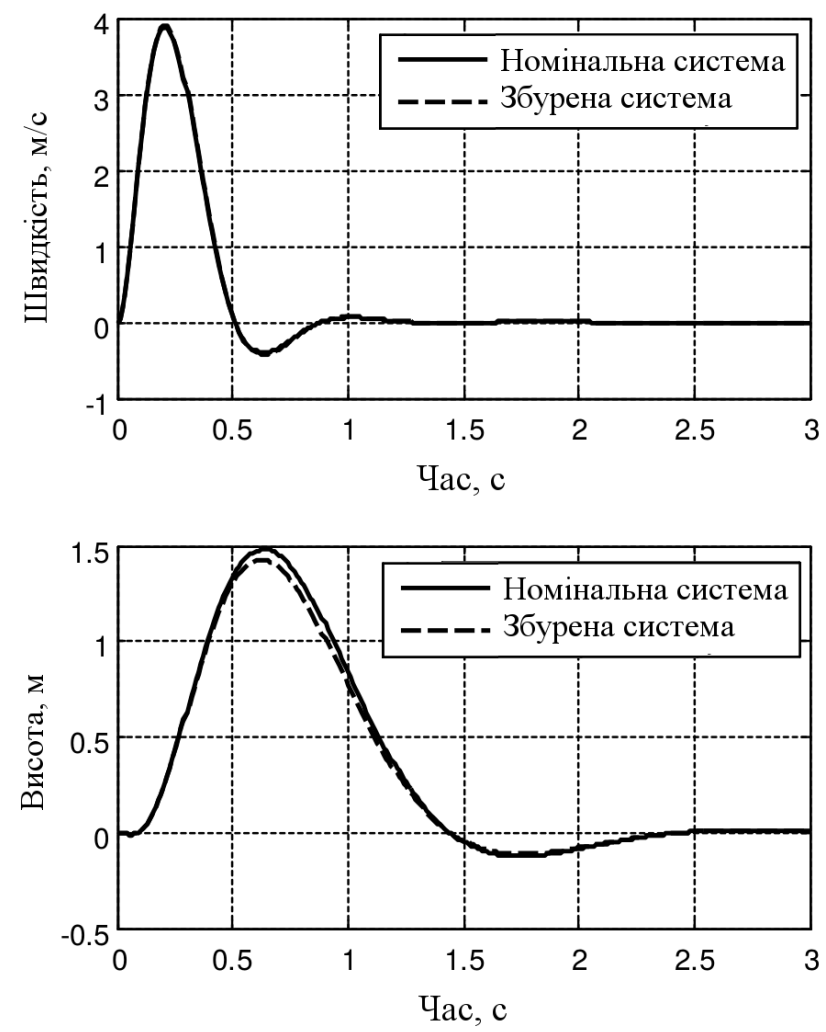

Рис. 4. Результати моделювання синтезованої системи для вхідного імпульсного впливу. 
Вважається, що синтезована система складається з об'єкта управління і регулятора, що описуються матричним передатним функціями $\mathbf{G}(s), \mathbf{K}(s)$ відповідно. Узагальнений об'єкт управління є системою з двома входами та двома виходами. Вектор $\mathbf{w} \epsilon$ зовнішній вхід, який у загальному випадку складається із збурень, вимірювальних шумів та командних сигналів. Вхідний вектор $\mathbf{u}$ представляє собою сигнали управління. Вихідний вектор $\mathbf{z}$ визначає якість процесів управління. Наприклад, він може бути охарактеризований похибкою відстеження командного сигналу, яка дорівнює нулю в ідеальному випадку. Вихідний вектор у представляє собою вектор спостережуваних сигналів, які використовуються для організації зворотних зв'язків. Передатна функція від входу $\mathbf{w}$ до виходу $\mathbf{Z}$ позначається як $\mathbf{W}_{w}^{z}$. Отже, головною задачею $H_{\infty}$ - синтезу $€$ вибір такого контролера $\mathbf{K}(s)$, який мінімізує норму $\left\|\mathbf{W}_{w}^{z}\right\|_{\infty}$. Реалізація $H_{\infty}$-синтезу базується на розв'язанні рівнянь Ріккаті з урахуванням виконання деяких обмежень [12]. Одним із методів, що використовується під час $H_{\infty}$ синтезу, є метод змішаної чутливості, для якого критерій оптимізації $H_{\infty}$ - синтезу $є$ таким [12]

$$
J(\mathbf{G}, \mathbf{K})=\left\|\left[\begin{array}{c}
\mathbf{W}_{1}(\mathbf{I}+\mathbf{G K})^{-1} \\
\mathbf{W}_{2} \mathbf{K}(\mathbf{I}+\mathbf{G K})^{-1} \\
\mathbf{W}_{3} \mathbf{G K}(\mathbf{I}+\mathbf{G K})^{-1}
\end{array}\right]\right\|_{\infty},
$$

тут $\mathbf{W}_{1}, \mathbf{W}_{2}, \mathbf{W}_{3}$ - вагові передатні функції чутливості системи, функції чутливості за управлінням та комплементарної функції чутливості системи [12].

Постановка задачі оптимізації з урахуванням виразу (5) набуває вигляду

$$
\mathbf{K}_{\text {опт }}=\arg \inf _{\mathbf{K}_{\text {опт }} \mathbf{K}_{\text {дог }}} J(\mathbf{G}, \mathbf{K}) .
$$

Результати моделювання підтверджують робастну стійкість системи.

Висновки. Здійснено вибір неортогональної конфігурації на основі характеристик кореляційної матриці похибок.

Отримано математичну модель каналу поздовжнього руху БПЛА 3 урахуванням надмірності вимірювальної системи на основі одноосних інерціальних датчиків.

Виконано проектування робастної системи управління на основі $H_{\infty}$-синтезу.

Поєднання надмірності навігаційної інформації та робастного контролера забезпечує покращання якості функціонування БПЛА в складних умовах реальної експлуатації.

Отримані результати можуть бути корисними для літальних апаратів іншого типу.

\section{ЛІТЕРАТУРА}

1. Cheng J., Dong J., Landry R.J., Chen D.A. Novel optimal configuration form redundant MEMS inertial sensors based on the orthogonal rotation method. Sensors, 2014, vol. 14(8), pp. 13661-13678.

2. Nilsson J.O., Skog I., Handel P. An open-source multi inertial measurement unit (MIMU) platform. Inertial Sensors and Systems

3 Sushchenko O. A., Bezkorovainyi Y. N., Novytska N. D. Nonorthogonal redundant configurations of inertial sensors, 2017 IEEE 4th International Conference Actual Problems of Unmanned Aerial Vehicles Developments (APUAVD).

4 Епифанов А.Д. Избыточные системы управления летательными аппаратами. Москва: Машиностроение, 1978. 178 с. 
5 Sushchenko O. A., Bezkorovainyi Y. N., Novytska N. D. Theoretical and Experimental Assessments of Accuracy of Nonorthogonal MEMS Sensor Aarrays / EasternEuropean Journal of Enterprise Technologies , no. 3, pp. 78-87.

6 Holland G.J., Webster P.J., Curry J.A. et al. The aerosonde robotic aircraft: a new paradigm for environmental observations, Bulletin of the American meteorological society, vol. 82, no. 5, 2001, pp.889-901.

7 D. McLean. Automatic Flight Control Systems. Prentice Hall, Inc., 1990, 593 p.

8 Jeromel J.C., Peres P.L., Souza S.R. Convex Analysis of Output Feedback Control Problems: Robust Stability and Performance, IEEE Trans, on Automatic Control. -1996. - Jul. - Vol. 41, № 7. - P. 903-1003.

9 AeroSim - Aerospace Technology. Mode of direct access: AeroSimwww.aerospacetechnology.com/contractors/training/aerosim/

10 Tunik A.A., Kim J.C., Yoo C.S. The Parameter Optimization of Aircraft's Control Law from the Viewpoint of Some Airworthiness Requirements // Proceedings of the 12th Korea Automatic Control Conf. “97 KACC”. ICASE Publ. - Seoul. -1997. - P. 1651-1654.

11 Stevens Brian L. Aircraft Control and Simulation / Brian L. Stevens, Frank F., Lewis.- [2nd ed.]. - John Wiley \& Sons Inc., 2003. - 665 p.

12 Skogestad S. Multivariable Feedback Control / Skogestad S., Postlethwaite I. - New York: Jonh Wiley, 1997. - 559 p.

\section{Sushchenko O.A., Bezkorovaynii Yu.M., Novytska N.D., Golytsin V.O. SYNTHESIS OF A UNIVERSAL UAV REGULATOR FOR A VIRTUAL NON- ORTHOGONALLY CONFIGURATIVE INERCIAL SENSORS}

The article is focused on the problems of the synthesis of robust control systems designed for operation on unmanned aerial vehicles. The main goal of the research is to develop an algorithm for synthesizing the robust law of unmanned aerial vehicle movement using a non-orthogonal measuring instrument, which represents the redundant configuration of gyroscopic sensors based on the technology of microelectromechanical systems. The development of the controller was carried out on the basis of robust structural synthesis. To achieve this goal, a model of the longitudinal movement of an unmanned aerial vehicle was developed. The state, control, and observation matrices of this model were determined using Aerosim technology using the MatLab system.

To solve this problem, methods of the theory of flight control were used in terms of creating a model of the longitudinal movement of the unmanned aerial vehicle; methods for constructing redundant non-orthogonal configurations of inertial sensors of moving vehicles; methods of modern control theory regarding the creation of robust structural synthesis algorithms, and methods of mathematical modeling.

The article presents the results of modeling a synthesized system in the form of transient processes for step and impulse inputs. The given graphical dependences demonstrate a high quality of control processes under the action of disturbing influences. The results can be useful for moving vehicles of a wide class, which use redundant measuring systems, but it is the most appropriate to use them in the problems of controlling unmanned aerial vehicles.

Key words: control system, nonorthogonal device, inertial sensor, redundancy, robust controller. 